\title{
The association between sexually transmitted pathogens and cervical intra-epithelial neoplasia in a developing community
}

\author{
A B M Kharsany, A A Hoosen, J Moodley, J Bagaratee, E Gouws
}

\begin{abstract}
Objective-To determine the association of sexually transmitted pathogens in women with cervical intra-epithelial neoplasia (CIN).

Setting-An urban tertiary referral hospital serving a large indigent developing community.

Participants- $\mathbf{4 8}$ women attending a colposcopy clinic and 49 women attending a family planning clinic.

Methods-Vaginal, endocervical, rectal swab specimens and sera were collected for the detection of sexually transmitted pathogens. Cervical cytology was performed on all patients. Women attending the colposcopy clinic had confirmation of abnormal cervical cytology by colposcopic directed biopsy.

Results-The mean age of women with CIN (33 years) was significantly greater than that of the women without CIN (28 years) and that of the family planning group (26 years). There was a high prevalence of sexually transmitted pathogens in all women. A significantly higher prevalence of bacterial vaginosis was found in women with CIN compared to those without $(50 \%$ vs $20 \%$; $=0.034)$. The human papilloma virus (HPV) was detected in $46 \%$ of women with CIN and $65 \%$ of those without CIN. Chlamydia trachomatis (21\%) and Trichomonas vaginalis (39\%) were detected frequently in women with CIN. C. trachomatis (14\%-21\%) was detected more frequently than Neisseria gonorrhoeae (3-5\%) in all asymptomatic women studied.
\end{abstract}

Conclusion-This study demonstrates a high prevalence of sexually transmitted pathogens in women with and without CIN as well as family planning clinic attenders. Bacterial vaginosis was a significant finding in women with CIN. C. trachomatis was detected in a high proportion of all women studied and found more commonly than $N$. gonorrhoeae. We therefore recommend that all women attending gynaecological services in a developing community be investigated and treated for sexually transmitted diseases.

(Genitourin Med 1993;69:357-360)

\section{Introduction}

Extensive research has been performed to establish the aetiology of cervical intra-epithe- lial neoplasia (CIN) and invasive carcinoma of the cervix. Epidemiological evidence correlating early onset of sexual intercourse and multiple sexual partners with CIN suggest that these conditions are sexually transmitted. ${ }^{12}$ Recent evidence has shown the human papilloma virus (HPV) to be an important co-factor in the development of $\mathrm{CIN}$ and subsequent carcinoma of the cervix. ${ }^{3}$ Prevalence rates for HPV in CIN I-III of $70-100 \%$ have been reported. ${ }^{4} \mathrm{HPV}$ has also been stated to be the causal agent in $80-100 \%$ of invasive cervical cancer. ${ }^{45}$

It is well established that in the presence of a single sexually transmitted infection, there is a greater likelihood of concomitant, sexually transmitted pathogens. This study, was therefore, undertaken to identify sexually transmitted agents in women with abnormal cervical cytology (including HPV changes).

Subjects and methods

A total of 48 women attending the colposcopy clinic at King Edward VIII Hospital (KEH), Durban were investigated. All were referred from local family planning clinics with abnormal cervical cytological findings. Twenty-eight of these were confirmed to have CIN alone or CIN-HPV on colposcopy and histology following colposcopic directed biopsies. These 28 women formed the study group. For purposes of comparison, two groups of women were regarded as controls. The first group consisted of 20 women in whom colposcopy directed biopsies did not reveal CIN. The second group consisted of 49 women attending the family planning clinic at $\mathrm{KEH}$, in whom Papanicolaou stained cervical smears revealed no abnormality.

Excluded from the study were women who were menstruating, had douched on the day of the study, and who had been on antibiotic treatment within the previous month.

Informed consent was obtained and each women was interviewed to ascertain age, marital status, pregnancy status, contraceptive and sexual history. All subjects were informed of the procedures to be performed. These included a vaginal examination and a cervical biopsy when necessary.

\section{Clinical examination}

Each woman underwent a general and gynaecological examination. The vulva was inspected for evidence of genital ulcerations and condylomata accuminata. The patient was then placed in the lithotomy position and 
a vaginal speculum moistened with sterile water was passed. The appearance of vaginal secretions was recorded. Specimens for microbiology were collected at this stage, thereafter a colposcopic examination was performed.

\section{Microbiological methods}

Vaginal secretions were collected from the posterior fornix with a polypropylene pipette and used to measure the $\mathrm{pH}$; perform the amine odour test, and for preparation of a wet smear. A few drops of secretion were inoculated into a modified Diamonds medium $^{6}$ for the cultivation of Trichomonas vaginalis. Wet preparations were examined at the patient's side for epithelial cells, inflammatory cells, "clue cells", motile trichomonads, yeasts and bacteria.

Vaginal secretion specimens were also obtained on cotton tipped swabs for inoculation onto selective human blood (SHB) agar, ${ }^{7}$ Sabourauds medium and Shepards A7 agar $^{8}$ for the isolation of Gardnerella vaginalis, yeasts and genital mycoplasmas respectively.

Endocervical specimens were collected with cotton tipped swabs and inoculated onto modified New York City Medium (MNYC), ${ }^{9}$ Shepards A7 agar and virus transport media for the isolation of Neisseria gonorrhoeae, genital mycoplasmas and herpes simplex virus respectively. One swab was rolled onto a clean glass slide, for the detection of Chlamydia trachomatis antigen (Microtrak, Syva, USA). Endourethral and rectal mucosal swabs were inoculated onto MNYC for the isolation of $N$. gonorrhoeae.

All bacterial and yeast isolates were identified by conventional laboratory methods. The modified Diamonds' medium was examined daily for seven days for motile trichomonads. A diagnosis of bacterial vaginosis was made according to the criteria recommended by Amsel et $a l^{10}$ that is, on the presence of any three of the following four signs: (a) a characteristic homogenous discharge, (b) vaginal $\mathrm{pH}>4 \cdot 5$, (c) release of "fishy" amine odour from vaginal secretion when mixed with $10 \%$ $\mathrm{KOH}$ and, (d) the presence of "clue" cells on microscopy.

Venous blood was drawn from each woman for serological tests for syphilis, hepatitis $\mathrm{B}$ surface antigen ( $\mathrm{HBs} \mathrm{Ag}$ ) and antibody to the human immunodeficiency virus (HIV). The Rapid Plasma Reagin (RPR) test (Becton Dickenson) was used to screen for syphillis. All reactive sera were titred and subjected to confirmatory teststhe Treponema pallidum haemmaglutination (TPHA) (Fujirebio) or the Fluorescent Treponemal Antibody Absorbent (FTA-Abs) (Wellcome) tests. Hepatitis B surface antigen was detected by radioimmunoassay (Ausria, Abbott). HIV antibody testing was performed using a recombinant HIV-1/HIV-2 Elisa kit (Abbott).

\section{Cytology and colposcopy}

Smears were obtained with the use of Ayres spatulae from the squamocolumnar junctions of the cervical epithelium for Papanicolaou stain. Smears were classified by standard criteria. Colposcopy was performed with a Zeiss Colposcope (OPMi-I). Standard predefined terminology ${ }^{11}$ was used to describe colposcopic findings and directed biopsies were taken when indicated.

\section{Histopathology}

Colposcopic directed tissue biopsy specimens were processed by standard histological methods. Classification followed the CIN method. The appearance of koilocytes was taken as evidence of HPV.

\section{Statistical analysis}

For categorical data, percentages were calculated for each group and statistically analysed using the chi square test. A $p$ value of $\leqslant 0.05$ was considered significant. Where overall significance was found, the differences among the group percentages were further investigated, again using chi square tests. For these multiple comparisons (investigating the difference between all possible 2-group combinations), Bonferroni's adjustment was used to protect the Type 1 error rate.

Analysis of variance was performed on continuous data to compare the means of the three groups. Where the ANOVA Fstatistic was found to be significant, Duncan's multiple-range test was used for post-hoc multiple comparisons.

\section{Results}

\section{Clinical data}

The clinical and behavioural characteristics of all subjects are shown in table 1 . The mean age of women with CIN was significantly greater than that of either of the control

Table 1 Clinical and behavioural characteristics

\begin{tabular}{|c|c|c|c|}
\hline & \multicolumn{2}{|c|}{ Colposcopy clinic $(n=48)$} & \multirow{2}{*}{$\begin{array}{l}\text { Family } \\
\text { planning } \\
\text { clinic } \\
(n=49)\end{array}$} \\
\hline & $\begin{array}{l}\text { Women with } C I N \\
(n=28)\end{array}$ & $\begin{array}{l}\text { Women without CIN } \\
(n=20)\end{array}$ & \\
\hline $\begin{array}{l}\text { Mean age in years (range) } \\
\text { Mean parity (range) } \\
\text { No. of single women (\%) } \\
\text { Mean lifetime no. of sexual partners (range) } \\
\text { Mean age of first intercourse in years (range) } \\
\text { Contraception (\%) }\end{array}$ & $\begin{array}{l}32 \cdot 9(25-47)^{\star} \\
3 \cdot 0(0-8) \\
18(64 \cdot 2) \\
2 \cdot 8(1-10) \\
17 \cdot 9(15-21)\end{array}$ & $\begin{array}{l}27 \cdot 7(18-52) \dagger \\
2 \cdot 0(0-4) \\
17(85 \cdot 0) \\
3 \cdot 0(1-8) \\
17 \cdot 8(15-21)\end{array}$ & $\begin{array}{l}25 \cdot 5(16-38) \ddagger \\
2 \cdot 0(0-6) \\
28(57 \cdot 1) \\
2 \cdot 1(1-10) \\
17 \cdot 6(14-28)\end{array}$ \\
\hline $\begin{array}{l}\text { Parental progesterone } \\
\text { Oral contraception } \\
\text { Intra-uterine contraceptive device } \\
\text { None }\end{array}$ & $\begin{aligned} 11 & (39 \cdot 3) \\
11 & (39 \cdot 3) \\
0 & (0 \cdot 0) \\
6 & (21 \cdot 4)\end{aligned}$ & $\begin{aligned} 10 & (50 \cdot 0) \\
4 & (20 \cdot 0) \\
1 & (5 \cdot 0) \\
5 & (25 \cdot 0)\end{aligned}$ & $\begin{aligned} 34 & (69 \cdot 4) \\
11 & (22 \cdot 4) \\
4 & (8 \cdot 2) \\
0 & (0 \cdot 0)\end{aligned}$ \\
\hline
\end{tabular}

Duncan's multiple range test: ${ }^{\star} \mathrm{vs}+\mathrm{p}<0.05 ;{ }^{\star} \mathrm{vs} \ddagger \mathrm{p}<0.05$ 
Table 2 Cytology, colposcopy and histology findings of women attending colposcopy clinic

\begin{tabular}{|c|c|c|c|c|c|c|}
\hline & \multicolumn{2}{|c|}{ Cytology $n=48$} & \multicolumn{2}{|c|}{ Colposcopy $n=48$} & \multicolumn{2}{|c|}{ Histology $n=45^{\star}$} \\
\hline & No. & $\%$ & No. & $\%$ & No. & $\%$ \\
\hline $\begin{array}{l}\text { HPV } \\
\text { CIN } \\
\text { CIN-HPV } \\
\text { Normal }\end{array}$ & $\begin{array}{r}4 \\
26 \\
18 \\
0\end{array}$ & $\begin{array}{r}8 \cdot 3 \\
54 \cdot 2 \\
37 \cdot 5\end{array}$ & $\begin{array}{r}8 \\
17 \\
20 \\
3\end{array}$ & $\begin{array}{r}16 \cdot 7 \\
35 \cdot 4 \\
41 \cdot 6 \\
6 \cdot 3\end{array}$ & $\begin{array}{r}13 \\
15 \\
13 \\
4\end{array}$ & $\begin{array}{r}28.9 \\
33.3 \\
28.9 \\
8.9\end{array}$ \\
\hline
\end{tabular}

${ }^{\star}$ In 3 women colposcopic examination was normal.

groups $(\mathrm{p}<0.05)$. There were no significant differences with regard to marital status amongst the groups. Women in the $\mathrm{CIN}$ group had more pregnancies than those in the control groups but this was not statistically significant. The commonest form of contraception used in all groups was parenteral progesterone (55 women).

\section{Cytology colposcopy and histology}

The cytological, colposcopic and histological findings of the 48 women attending the colposcopy clinic are shown in table 2 . CIN in combination with HPV was detected by cytology in 18 of 48 women $(37 \cdot 5 \%)$. Histology, however, confirmed this finding in 13 of the 18 women only. In three women the colposcopic examination was normal and therefore no specimens were taken for histology.

\section{Microbiology}

Sexually transmitted micro-organisms isolated from the endocervix and vagina are shown in table 3 . With regard to recognised sexually transmitted pathogens, $N$. gonorrhoeae was found in $3.6 \%$ to $5.0 \%$, C. trachomatis in $14.0 \%$ to $21.4 \%$ and $T$. vaginalis in $15.0 \%$ to $39.3 \%$ of subjects. Herpes simplex virus was not cultured from the endocervix of any patient. HPV was diagnosed histologically in 13 of $28(46.4 \%)$ women with CIN and 13 of $20(65.0 \%)$ women without CIN. It was not detected in any subject attending the family planning clinic as these had normal Papanicolaou smears. Overall (with the exception of HPV), there were no significant differences in the detection of any sexually transmitted organisms amongst the groups investigated.

Whilst $G$. vaginalis was isolated from the vagina of up to $79.6 \%$ of women, the syndrome of bacterial vaginosis was diagnosed clinically in $50 \%$ of women with CIN compared to $20 \%$ of women without CIN $(p=0.034)$.

The results of serological tests are also shown in table 3. Both syphilis serology and hepatitis B surface antigen tests were positive in a similar number of women in each of the groups. In none of the women tested was antibody to HIV detected.

\section{Discussion}

Lower genital tract infections whether asymptomatic or manifest by vaginal discharge are a frequent problem in sexually active women. This study looked at the presence of sexually transmitted pathogens in a condition which is known to be sexually transmitted. Demographic data showed that women with CIN were older than control women $(32.9$ years vs 27.7 years and 25.5 years - table 1 ). Although age at first intercourse was not significantly different amongst the groups, women with CIN by virtue of being older were thus exposed to coitus for a longer period and therefore to a coitally transmitted agent.

Rotkin ${ }^{1}$ reported that barrier type contraception might be protective against unknown carriage of agents associated in the aetiology of CIN. In our study, no women used barrier form of contraception; in fact $21 \%$ of women with CIN did not use any form of contraception. These observations confirm the important influence of sexual behaviour as a risk factor for CIN.

Bacterial vaginosis is a syndrome characterised by homogenous vaginal discharge in which there is an alteration of vaginal flora with $G$. vaginalis as the predominant organism. The isolation of $G$. vaginalis in all groups studied was high, ranging from $75.0 \%$ to $79.6 \%$; however, the syndrome of bacterial vaginosis was detected significantly more often in women with CIN than those without

Table 3 Micro-organisms detected in cervical and vaginal specimens and results of serological tests

\begin{tabular}{|c|c|c|c|c|c|c|}
\hline & \multicolumn{4}{|c|}{ Colposcopy clinic $(n=48)$} & \multirow{2}{*}{\multicolumn{2}{|c|}{$\begin{array}{l}\text { Family planning } \\
\text { clinic }(n=49)\end{array}$}} \\
\hline & \multicolumn{2}{|c|}{ Women with CIN $(n=28)$} & \multicolumn{2}{|c|}{ Women without CIN $(n=20)$} & & \\
\hline & No. & $\%$ & No. & $\%$ & No. & $\%$ \\
\hline $\begin{array}{l}\text { Cervical } \\
\text { N. gonorrhoeae } \\
\text { C. trachomatis } \\
\text { Herpes simplex virus } \\
\text { M. hominis } \\
\text { U. urealyticum } \\
\text { HPV }\end{array}$ & $\begin{array}{c}1 \\
6 \\
0 \\
16 \\
13 \\
13^{\star}\end{array}$ & $\begin{array}{r}3 \cdot 6 \\
21 \cdot 4 \\
0 \cdot 0 \\
57 \cdot 1 \\
46 \cdot 4 \\
46 \cdot 4\end{array}$ & $\begin{array}{r}1 \\
4 \\
0 \\
10 \\
7 \\
13^{\star}\end{array}$ & $\begin{array}{r}5.0 \\
20.0 \\
0.0 \\
50.0 \\
35.0 \\
65.0\end{array}$ & $\begin{array}{r}2 \\
7 \\
0 \\
21 \\
16 \\
0\end{array}$ & $\begin{array}{r}4.0 \\
14.0 \\
0.0 \\
44.9 \\
32 \cdot 7 \\
0\end{array}$ \\
\hline $\begin{array}{l}\text { Vaginal } \\
\text { C. albicans } \\
\text { T. vaginalis } \\
\text { M. hominis } \\
\text { U. urealyticum } \\
\text { G. vaginalis } \\
\text { Bacterial vaginosis }\end{array}$ & $\begin{array}{l}7 \\
11 \\
18 \\
15 \\
20 \\
14 \dagger\end{array}$ & $\begin{array}{l}25 \cdot 0 \\
39 \cdot 3 \\
64 \cdot 3 \\
53 \cdot 6 \\
77 \cdot 4 \\
50 \cdot 0\end{array}$ & $\begin{array}{c}9 \\
3 \\
14 \\
13 \\
15 \\
4 \ddagger\end{array}$ & $\begin{array}{l}45.0 \\
15.0 \\
70.0 \\
65.0 \\
75.0 \\
20.0\end{array}$ & $\begin{array}{r}8 \\
12 \\
28 \\
25 \\
39 \\
18\end{array}$ & $\begin{array}{l}16 \cdot 0 \\
24 \cdot 5 \\
57 \cdot 1 \\
51 \cdot 2 \\
79 \cdot 6 \\
36 \cdot 7\end{array}$ \\
\hline $\begin{array}{c}\text { Serological tests } \\
\text { Syphilis } \\
\text { HBs Ag } \\
\text { HIV Ab } \\
\end{array}$ & $\begin{array}{l}4 \\
3 \\
0\end{array}$ & $\begin{array}{r}14.3 \\
10.7 \\
0.0\end{array}$ & $\begin{array}{l}6 \\
3 \\
0\end{array}$ & $\begin{array}{r}30.0 \\
15.0 \\
0.0\end{array}$ & $\begin{array}{l}9 \\
4 \\
0\end{array}$ & $\begin{array}{r}18.4 \\
8.0 \\
0.0\end{array}$ \\
\hline
\end{tabular}


( $50 \%$ vs $20 \%$; $p=0.034)$. A possible reason for this association is that local changes such as the elevation of vaginal $\mathrm{pH}$ may facilitate the action of other agents in the pathogenesis of CIN.

Human papilloma virus infection was confirmed histologically in a total of 26 of 48 $(54 \cdot 2 \%)$ women including 13 of $28(46.4 \%)$ women with CIN (table 2). This finding is similar to that of Guijon et al ${ }^{12}$ who also detected HPV infections in 15 of 33 (45\%) women with $\mathrm{CIN}$ and confirms the strong association of HPV with CIN. It has been reported that various subtypes of HPV have a role in the pathogenesis of CIN and cervical cancer. ${ }^{5}$ However, subtyping of HPV by in situ-hybridisation was not performed in this study owing to lack of resources.

Previous local studies on symptomatic women with cervical infections have shown a higher prevalence of $N$. gonorrhoeae than $C$. trachomatis. ${ }^{13}{ }^{14}$ However, this study in asymptomatic women showed a much higher prevalence of $C$. trachomatis $(14.0 \%$ to $21.4 \%$ ) compared with $N$. gonorrheoae $(3.6 \%$ to $5.0 \%$ ). Studies performed mainly in affluent societies have detected a high incidence of chlamydial infections in general practice and colposcopy clinics. ${ }^{15}$ Our findings strongly confirm the important role of $C$. trachomatis in silent infections in the local indigenous population.

The isolation of other sexually transmitted organisms from the groups studied were not different from that reported in the general population. ${ }^{1617}$ These figures are much higher than those reported from developed communities. ${ }^{18}$ It would therefore be effective and cost beneficial to screen for sexually transmitted pathogens in all women attending gynaecological services at our hospital.

Guijon et al ${ }^{12}$ found that increased number of life time sexual partners, the unmarried state and multiparity were more common in women with CIN than in a comparable group of women attending a family planning clinic. Our study did not confirm these sexual behavioural characteristics. This may be due to the high incidence of sexually transmitted diseases found in the local population.

Wasserheit ${ }^{19}$ reviewed the inter-relationships between human immunodeficiency virus (HIV) infection and other sexually transmitted diseases in a meta-analysis of 163 studies and showed that the risk of HIV transmission is increased in the presence of genital ulcer disease as well as non-ulcerative conditions such as chlamydial infections, gonorrhoea and trichomoniasis. At the time of this study, none of the women were HIV antibody positive; however, a subsequent study showed a $5 \%$ prevalence in colposcopy clinic attenders. ${ }^{20}$ The early and appropriate treatment of cervico-vaginal infections would therefore reduce the transmission of HIV infection.

\section{Conclusion}

Our study demonstrates a high prevalence of sexually transmitted pathogens in women with and without CIN as well as those attending the family planning clinic. Bacterial vaginosis was a significant finding in women with CIN. C. trachomatis was detected in a high proportion of all women studied and found more commonly than $N$. gonorrhoeae. We therefore recommend that all women attending gynaecological services in a developing community be investigated and treated for sexually transmitted diseases.

We thank Professor J van den Ende for his advice in the preparation of this manuscript. We also thank the staff of the colposcopy and family planning clinics at King Edward VIII Hospital for their kind assistance. Rotkin ID. A comparison review of key epidemiological studies in cervical cancer related to current searche
transmissible agents. Cancer Res 1973;33:1353-67.

2 Wright VC, Riopelle MA. Age at beginning of coitus versus chronologic age as a basis for Papanicolaou smear screening: An analysis of 747 cases of preinvasive disease. Am $\mathcal{F}$ Obstet Gynecol 1984;149:824-30.

3 Reeves WC, Brinton LA, Garcia M, et al. Human papillomavirus infection and cervical cancer in Latin America. N Engl f Med 1989;320:1437-41.

4 Meijer CJLM, van den Brule AJC, Sniders PJF, et al. Detection of human papillomavirus in cervical scrapes by the polymerase chain reaction in relation to cytology: by the polymerase chain reaction in relation to cytology: possible implications for cervical cancer screening: In: Epidemiology of Cervical Cancer and Human PapillomaEpidemiology of Cervical Cancer and Human Papilloma-
virus. Lyon: International Agency for Research on virus. Lyon: Internation

5 Munoz N, Bosch FX, De Sanjose S, et al. The causal link between human papillomavirus and invasive cervica cancer: a population based case control study in Colombia and Spain. Int $\mathcal{f}$ Cancer 1992;52:743-9.

6 Diamond LS. The establishment of various Trichomonads of man and animals in axenic cultures. f Parasitol 1957;43:488-90.

7 Greenwood JR, Pickett MJ, Martin WJ, Mack EG. Haemophilus vaginalis (Corynebacterium vaginale): method for isolation and rapid biochemical identification. Health Lab Sci 1977;14:102-6.

8 Shepard MC, Lunceford CD. Differential agar medium (A7) for identification of Ureaplasma urealyticum (human $T$ mycoplasmas) in primary cultures of clinical material. F Clin Microbiol 1976;3:613-25.

9 Young H. Cultural diagnosis of gonorrhoeae with modified New York City Medium (MNYC). Br $\mathcal{f}$ Venereal Dis 1978;54:36-40.

10 Amsel R, Totten PA, Spiegel CA, Chen KCS, Eschenbach D, Holmes KK. Non specific vaginitis: diagnostic criteria and microbial and epidemiologic associations. Am f Med 1983;74:14-22.

11 Report of the Committee on Terminology. New nomenclature for colposcopy. Obstet Gynecol 1976;48:123-4.

12 Guijon FB, Paraskevas M, Brunham R. The association of sexually transmitted diseases with cervical intraepithelial neoplasia: a case-control study. Am $\mathcal{F}$ Obstet Gynecol 1985;151:185-90.

13 Hoosen AA, Coetzee KD, van den Ende J. Microbiology of vaginal discharge in patients attending a sexually transmitted disease clinic in Durban. Paper presented at the Infectious Diseases and Sexually Transmitted Diseases Congress, Durban 14-16 October 1987 (abstract 040)

14 Hoosen AA, Quinlan DJ, Moodley J, Kharsany ABM, van den Ende J. Sexually transmitted pathogens in acute pelvic inflammatory disease. $S$ Afr Med $\mathcal{F}$ 1989;76: pelvic

15 Smith JR, Murdoch J, Carrington D, et al. Prevalence of Chlamydia trachomatis infection in women having cerChlamydia trachomatis infection in

16 Dietrich M, Hoosen AA, Moodley J, Moodley S. Urogenital tract infections in pregnancy at King Edward VIII Hospital, Durban, South Africa. Genitourin Med 1992;68:39-41.

17 O'Farrell N, Hoosen AA, Kharsany ABM, van den Ende J. Sexually transmitted pathogens in pregnant women in a rural South African community. Genitourin Med 1989; 65:276-80.

18 Hicks D, Brown V, Spencer RC. Evaluation of abnormal cervical cytology results in a genitourinary clinic. Genitourin Med 1989;65:348-9.

19 Wasserheit JN. Epidemiological synergy: inter-relationships between human immunodeficiency virus infection and other sexually transmitted diseases. Sex Transm Dis 1992;19:61-77.

20 Moodley J, Hoosen AA, Naidu S, Mayat N, Kharsany ABM. HIV status and sexually transmitted pathogens in Women attending a colpos 